\title{
PERANCANGAN MESIN PEMOTONGAN BAHAN BAKU GENTENG DENGAN SISTEM KENDALI PLC LOGIC SMART RELAY(SR3B101FU)
}

\author{
Dony Susandi, AsepRachmat, Yudi Samantha, Guntur Priyatna \\ FakultasTeknik - UniversitasMajalengka \\ Email :ds_777@ymail.com
}

\begin{abstract}
Genting raw materials cutting machine is cutting processing tool with the mechanical system work. Working system for each element of machine motion in this study using apneumatic control based mover. One important aspect of the method and manufacturing series systems through the use of automation technology is a programmable logic control (PLC) as the control system. One of the main problems in this research activity is the use of automation technology which can produce products quickly, accurately and efficiently. However, before doing it all, need to understand the operational characteristics of the machine it self, so in the design, manufacture and operation will be easier and get the results as expected. Through this study, the authors tried methods of improvements to the system control processing equipment raw materials, PLC is used as an interface to drive the motion of elements in Pneumatic pump for each motion element. This study focused on the design and construction of the driving element processing tool. The control system of cutting genting raw material is used SR3B101FU PLC (AC 220V) with a pneumatic drive system on the cutting element and pushing motion. The research methodology used in this study is divided into 3 parts, first control system design such as electricity, wiring and PLC programming, second are construction system design such as mechaninal contruction of cutting process and third analysis of control system such as pneumatic cylinder pressures and forces acting genting to determine capability of machine raw materials cutting and pushing process. Forces acting on the double acting cylinder is equal to $1252.86 \mathrm{~N}$ its mean cutting machines and encouragement to work at maximum mass of 127.71 $\mathrm{kg}$, while the mass of critical raw materials amounted to only $0.149 \mathrm{~kg}$ so that the machine has the capability to perform the cutting of raw materials and promoting material cutting results.
\end{abstract}

\section{Keyword :PLC, Pneumatik, Genting.}

\section{PENDAHULUAN}

Perkembangan teknologi manufaktur tidak terlepas dari adanya tuntutan-tuntutan, yaitu : Menghasilkan produk dalam waktu singkat dengan biaya rendah dan berkualitas, dapat mengubah variasi produk dan Sumber daya manusia (SDM). Agar memenuhi tuntutan tersebut, dalam menghasilkan suatu produk dibutuhkan seorang operator yang mempunyai skill tinggi dengan kompleksitas perlengakapannya (Dony Susandi, 2004).Mesin pemotongan bahan baku genting merupakan alat pemrosesan pemotongan bahan baku genting dengan sistem kerja mekanik. Sistem kerja untuk setiap elemen gerak mesin dalam penelitian ini menggunakan kendali penggerak berbasis pneumatik, dimana udara yang sudah dimampatkan (pneumatik) tersebut kemudian akan di distribusikan ke setiap elemen gerak fungsi pemotongan dan pendorongan bahan baku hasil pemotongan. Kontruksi mekanik dan elektronik dibuat berdasarkan desain sistem yang berfungsi untuk melakukan pemotongan dan pendorongan bahan baku genting. Proses pemotongan dilakukan secara konvensional yang dilakukan oleh seorang operator pemotongan dan pemindahan bahan baku hasil pemotongan ke alat penanganan material. Operator secara terus menerus melakukan proses pemotongan setelah bahan baku mengalami proses penggilingan. Salah satu metode dan aspek penting dalam rangkaian sistem manufaktur melaluipemanfaatan teknologi otomasi adalah Programmable logic 
control (PLC) sebagai sistem kendali.PLC adalah sebuah alat yang digunakan untuk menggantikan rangkaian sederetan relay yang dijumpai pada sistem kontrol proses Konvensional. PLC bekerja dengan cara mengamati masukan (melalui sensor-sensor terkait). Selanjutnya melakukan proses dan tindakan sesuai yang dibutuhkan, berupa menghidupkan atau mematikan keluaran (logik 0 atau 1, hidup atau mati). Dengan kata lain, PLC menentukan aksi apa yang harus dilakukan pada instrument keluaran berkaitan dengan status suatu ukuran atau besaran yang diamati (William Bolton, 2003). Terdapat empat komponen penting dalam kontruksialat pemrosesanyaitu sensor, actuator, analyzerdan drives. Penelitian in idifokuskan pada perancangan elemen penggerak dan konstruksi alat pemrosesan pemotongan bahan baku genting. Sistem kendali pemotongan bahan baku menggunakan PLC SR3B101FU (AC 220V) dengan system penggerak pneumatic pada elemen gerak pemotongan dan pendorongan. Penelitian ini bertujuan untuk mendapatkan model dari elemen kerja proses pemotongan dan pendorongan bahan baku terotomasi menggunakan PLC dan pneumatic sebagai penggerak mesin pemrosesan. Penelitian ini diharapkan mampu memberikan dampak pada peningkatan produktivitas proses pemotongan bahan baku genting yang berbasis teknologi otomasi.

\section{METODE PENELITIAN}

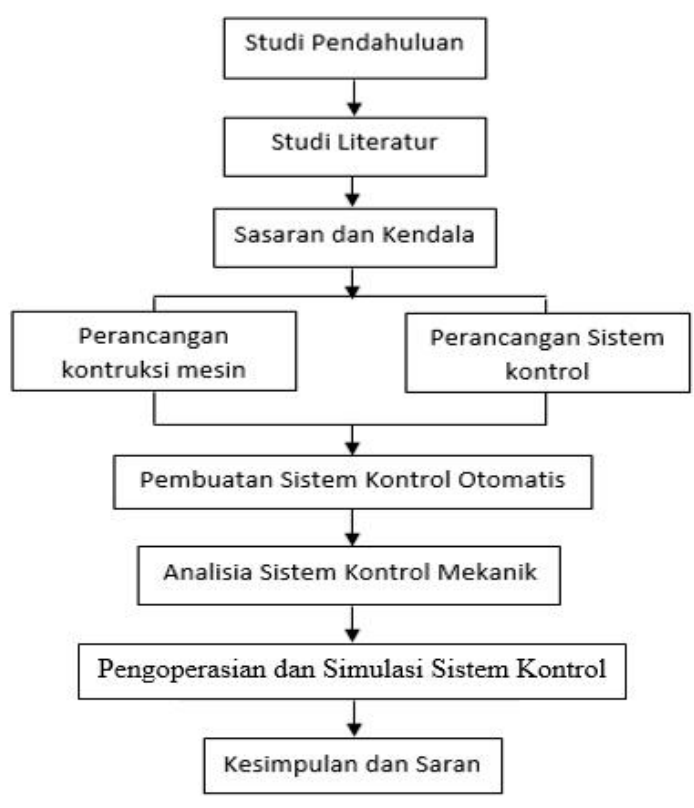

Gambar 1. Langkah Pemecahan Masalah
Perancangan Sistem Kontrol, proses pembuatan genteng diawali dengan pengolahan bahan mentah berupa tanah. Pengambilan tanah sebagai bahan baku genteng harus berdasarkan kelestarian lingkungan. Pengambilan tanah dilakukan dengan cara menyingkirkan lapisan bunga tanah dan tanah yang diambil adalah tanah dibagian bawah bunga tanah yang kurang lebih kedalamannya $25 \mathrm{~cm}$ dari permukaan tanah.

Dibutuhkan data empiris bahan baku genting sebagai penunjang dalam perencanaan mesin pemotongan bahan baku genting yaitu mengenai data sifat fisik bahan baku secara umum sehingga dapat memberikan gambaran untuk menentukan gaya penekanan kecepatan piston pemotongan berbasis pneumatik.

Tabel 1. Dimensi Bahan Baku

\begin{tabular}{|c|c|c|c|}
\hline Pengukuran & Lebar & Panjang & Tinggi \\
\hline Bahan Baku & $15 \mathrm{~cm}$ & $45 \mathrm{~cm}$ & $15 \mathrm{~cm}$ \\
\hline
\end{tabular}

\section{A. Perancangan Sistem Kontrol}

Perancangan sistem kontrol terbagi menjadi 3 bagian yaitu electricity, wiring dan programming. PLC yang digunakan adalah PLC Zelio Logic Smart Relay tipe SR3B101FU. Programming pada PLC adalah menentukan masukan dan keluaran yang di proses oleh PLC Zelio Smart Relay(Dedi, 2011) sehingga menghasilkan gerak pada elemen pemotongan dan pendorongan bahan baku genting.

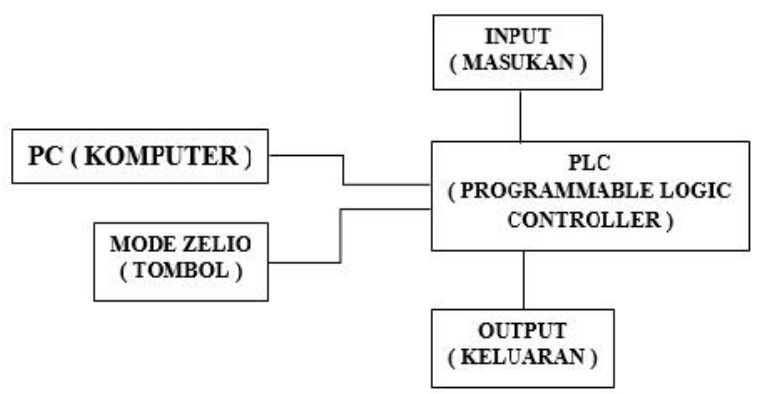

Gambar 2. Diagram Blok PLC

Untuk kelistrikan, kerja mesin menggunakan alternating current (AC 220V), rangkaian daya pada elemen kerja pemotongan dan pendorongan bahan baku genting menggunakan rangkaian daya saklar balik. Apabila K2 ditekan, selain sakelar K1 dihubungkan, kontak K1:2 akan membuka. Lingkaran arus selenoid K2 akan terhalang dan begitu pun sebaliknya (lihatgambar $3)$. 


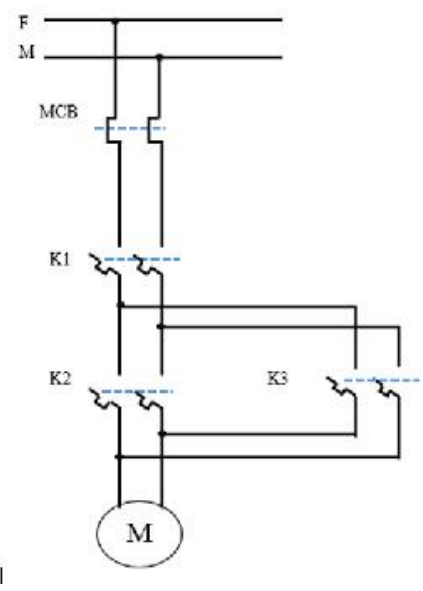

Gambar 3. Rangkaian Daya Saklar Balik

Silinder yang digunakan dalam sistem pneumatik pada penelitian ini menggunakan silinder gerak 2 langkah silinder (lihat gambar 4).

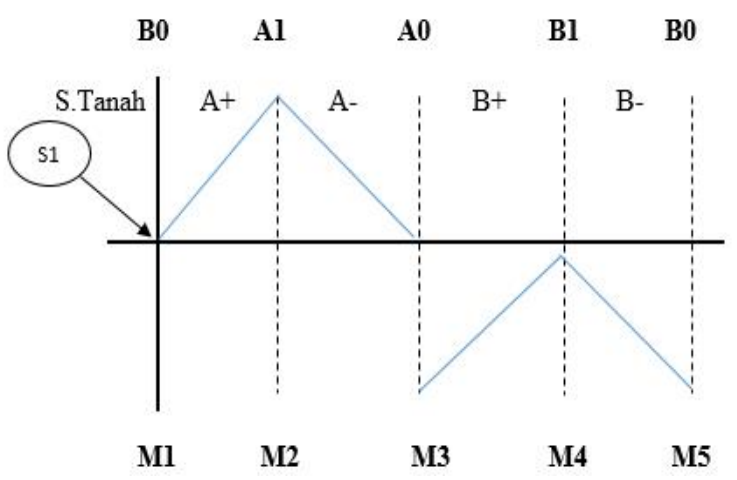

Gambar 4. Gerak 2 Langkah Silinder

Langkah berikutnya adalah penyusunan wiring (gambar 5) untuk PLC, setiap masukan dalam PLC digunakan sebagai kendali yang dibutuhkan oleh setiap elemen kerja mesin yaitu pemotongan dengan silinder gerak 2 langkah sebanyak 2 masukan dan elemen kerja mesin pendorongan dengan silinder gerak 2 langkah sebanyak 2 masukan sehingga terdapat minimal kebutuhan 4 masukan bagi PLC ditambah dengan 1 masukan main power dan 1 circuit braker.

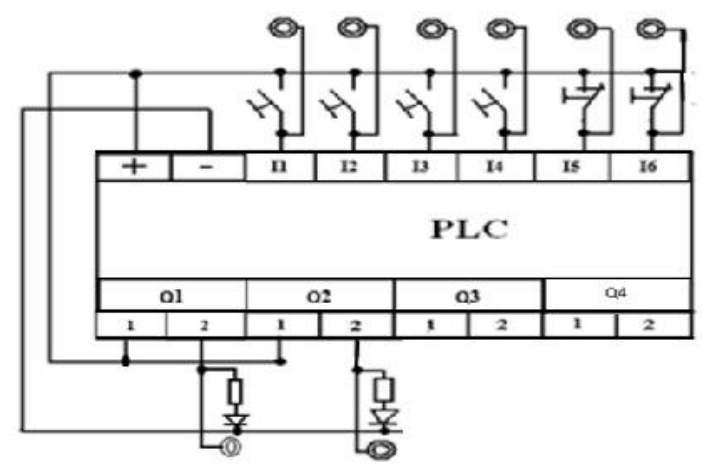

\section{Gambar 5.PLC Wiring}

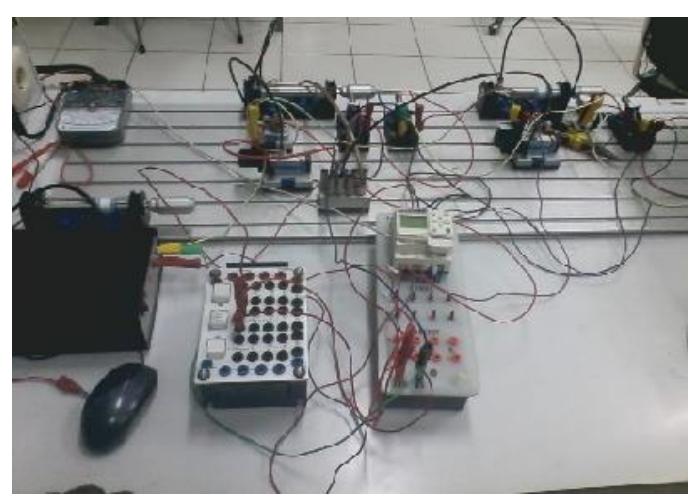

Gambar 6. Hasil Wiring

Rangkaian control gerak 2 silinder untuk pemotongan dan pendorongan bahan baku dapat dilihat pada gambar 7 .

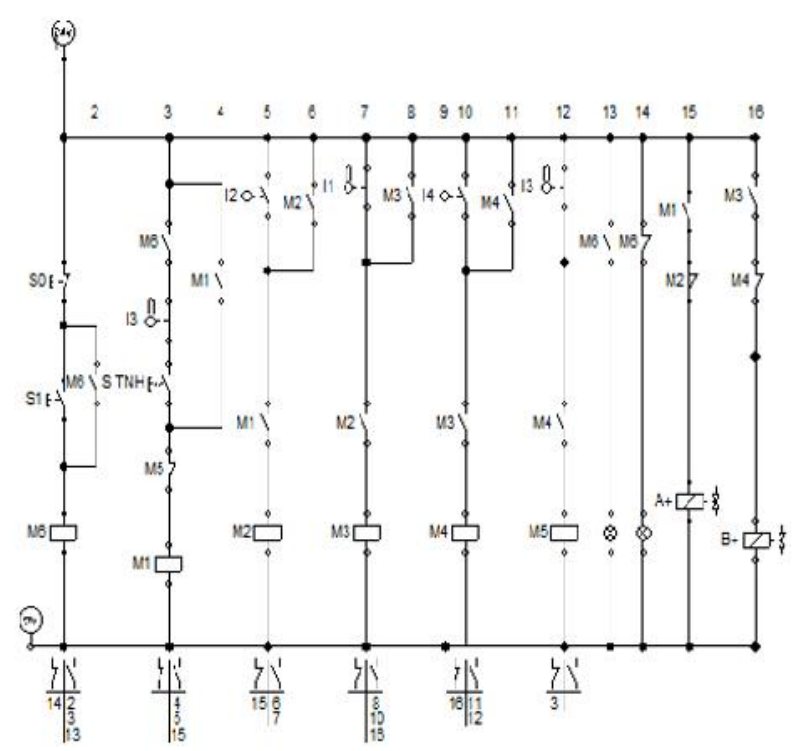

Gambar 7. Rangkaian Kontrol Gerak 2 Silinder

\section{B. Perancangan Kontruksi Mesin}

Prinsip kerja dari kontruksi pemotongan adalah memotong kebawah pada saat bahan baku sudah dalam ukuran yang diinginkan, akan kembali ke posisi semula sesudah proses pemotongan dilakukan. Alat kontrolnya berupa limit switch. Prinsip kerja dari kontruksi pendorongan adalah mendorong kedepan pada saat bahan baku sudah dalam ukuran yang diinginkan, akan kembali ke posisi semula sesudah proses pendorongan dilakukan. Alat kontrolnya berupa limit switch.

Prinsip kerja dari kontruksi mesin pemotong bahan baku ialah pada saat bahan baku keluar dari mesin penggiling, langkah pertama bahan baku dipotong sesuai dengan ukuran yang sudah ditentukan yaitu $45 \mathrm{~cm}$, kemudian tahap 
selanjutnya bahan baku akan melewati lintasan menuju ke tempat pendorongan, sehingga bahan baku yang sudah terpotong yang panjangnya 45 $\mathrm{cm}$ lalu didorong sesuai yang diinginkan yaitu 15 cm per bahan baku.

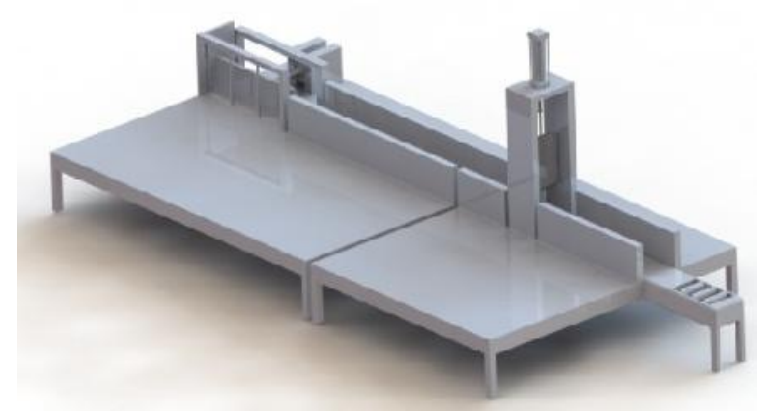

Gambar 8. Kontruksi Mesin Pemotong Bahan Baku Genteng

\section{Analisa Sistem Kontrol}

Parameter yang digunakan dalam mengukur kapabilitas adalah tekanan piston dangaya piston pada saat melakukan kerja proses pemotongan dan pendorongan (Andrew, 2003).

\section{a. LuasPenampang Piston}

$$
\mathrm{A}=\frac{1}{4} \pi
$$

$\mathrm{d}^{2}$.

\section{b. Tekanan Piston}

$$
\mathbf{P}=\frac{F}{A}=\frac{W}{A}=\frac{m_{h} g}{A} .
$$

dimana :

$$
\begin{array}{ll}
1 \mathrm{~kg} / \mathrm{cm}^{2} & =98,07 \mathrm{kPa} \\
1 \mathrm{kpa} & =1000 \mathrm{mpa}
\end{array}
$$

\section{Gaya Piston (F)}

$$
\mathrm{F}=\mathrm{A} \text {. }
$$$$
P \text {.. }
$$

\section{c. Gaya Double acting}

$$
\begin{aligned}
\mathrm{Fd} & =p \pi \\
\left(\frac{d 1^{2} d 2^{2}}{4}\right) & \ldots \ldots \ldots
\end{aligned}
$$

\section{HASIL DAN PEMBAHASAN}

Pemanfaatan pneumatic pada penelitian ini dipilih berdasarkan teknologi yang berkembang saat ini dengan penggunaanya yang lebih mudah dan aman serta dengan biaya yang relative tidak besar. Faktor-faktor yang dibutuhkan pada proses perancangan adalah kapabilitas mesin pemotong dan penorong yang dirancang dalamm elakukan proses pemotongan dan pendorongan bahan baku genting (Lihat gambar 8). Massa bahan organik dan anorganik diperhitungkan sebagai massa padatan tanah dalam penentuan berat jenis partikel tanah. Berat jenis partikel mempunyai satuan $\mathrm{Mg} \mathrm{m}^{-3}$ atau $\mathrm{g} \mathrm{cm}^{-3}$. Penentuan berat jenis partikel penting apabila diperlukan ketelitian pendugaan ruang pori total. Berat jenis partikel berhubungan langsung dengan berat volume tanah, volume udara tanah, serta kecepatan sedimentasi partikel di dalam zat cair. Penentuan tekstur tanah dengan metode sedimentasi, perhitungan-perhitungan perpindahan partikel oleh angin dan air memerlukan data berat jenis partikel. Untuk tanah mineral, $\rho s$ sering diasumsikan sekitar 2,65 $\mathrm{g} \mathrm{cm}^{-3}$ (Hillel, 1982).

\section{a. Volume bahan baku genting}

Volume bahanbakugenting $=15 \mathrm{~cm} \times 15 \mathrm{~cm} \mathrm{x}$ $0,25 \mathrm{~cm}=56,25 \mathrm{~cm}^{3}$

$$
\begin{aligned}
& m=\rho \text {. } \\
& v \text {.. } \\
& \begin{array}{l}
=2,65 \mathrm{gcm}^{-3} \times 56,25 \mathrm{~cm}^{3} \\
=149 \mathrm{gram}
\end{array} \\
& =\frac{149 \mathrm{gram}}{1000}=0,149 \mathrm{~kg}
\end{aligned}
$$

\section{b. Tekanan Piston}

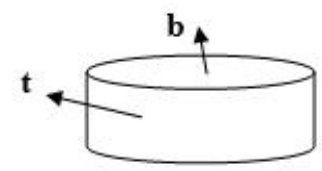

Gambar 9.LuasPenampang Piston

Tabel 2. Data Spesifikasi Cylinder Pneumatik Double ActingSMC-CDM2B20-100

\begin{tabular}{|l|l|}
\hline \multicolumn{2}{|c|}{ DOUBLE ACTING } \\
\hline Tekanan Maximum & $1,0 \mathrm{mPa}$ \\
\hline Tipe & SMC-CDM2B20-100 \\
\hline Diameter Batang & $2,2 \mathrm{~cm}$ \\
\hline Panjang & $15 \mathrm{~cm}$ \\
\hline Panjang Langkah & $15 \mathrm{~cm}$ \\
\hline Berat & $0,1 \mathrm{~kg}$ \\
\hline
\end{tabular}

Berdasarkan rumus2, diperoleh tekanan yang bekerja atau yang dihasilkan oleh piston adalah sebesar380 N/m dan dengan menggunakan rumus 3 maka besarnya gaya piston adalah1,46 N.

\section{c. Double acting piston}


DiperolehLuas Penampang piston berdasarkan rumus 1 dengan diameter batang2,2 $\mathrm{cm}$ adalah $3,7994 \mathrm{~cm}$.Silinder double acting memiliki dua saluran input dan setiap inputnya berfungsi sebagai pengendali dari piston, baik pada saat maju maupun pada saat mundur. Pada saat piston maju input pertama yang berfungsi dan pada saat mundur input kedua yang berfungsi.

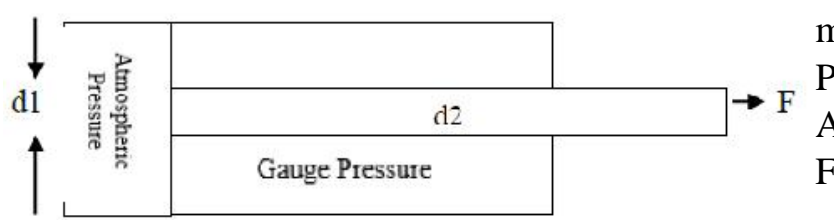

Gambar10.SaluranSilinderdouble acting

Dengan menggunakan rumus 4 , diperoleh gaya yang bekerja pada silinder double acting adalah sebesar 1252,86 N.

\section{KESIMPULAN}

Pekerjaan proses pemotongan dan pemindahan bahan baku genting ke bagian pencetakan merupakan proses yang dapat menyebabkan kecelakaan akibat beban kerja yang berlebihan. Dengan teknologi otomasi, proses pemotongan dapat menghindarkan operator/tenaga produksi terhindar dari kecelakaan langsung saat terjadi kecelakaan karena operator/tenaga produksi tidak secara langsung melakukan pemotongan bahan baku pada kondisi yang tidak nyaman saat berkerja.Gaya yang bekerja pada silinder double [6] na, Bandung. acting yaitu sebesar 1252,86 $\mathrm{N}$ artinya mesin pemotongan dan pendorongan dapat bekerja pada massa maksimal $127,71 \mathrm{~kg}$, sedangkan massa bahan baku genting hanya sebesar $0,149 \mathrm{~kg}$ sehingga mesin memiliki kapabilitas untuk melakukan pemotongan bahan baku dan pendorongan bahan baku hasil pemotongan.

\section{Satuan :}

$\begin{array}{lll}\mathrm{m} & \text { massa } & {[\mathrm{kg}]} \\ \mathrm{P} & \text { tekanan piston } & {[\mathrm{Pa}]} \\ \mathrm{A} & \text { luaspenampang } & {[\mathrm{cm}]} \\ \mathrm{F} & \text { gaya piston } & {[\mathrm{N}]}\end{array}$

\section{DAFTAR PUSTAKA}

[1] Hillel, D. 1982. Introduction to Soil Physics. Academic Press, New York.

[2] Bolton, William, 2003. Programmable Logic Controller (PLC) Sebuah Pengantar Edisi Ketiga.Jakarta: Erlangga.

[3] Andrew Parr, 2003. Hidrolika dan Pneumatika, Alih Bahasa Gunawan Prasetyo, Jakarta. Penerbit Erlangga.

[4] Dony Susandi, 2004. "Automatisasi Processing Equipment Dengan Menggunakan PLC Pada Mesin Bubut Konvensional (BV-20)". Bandung, Universitas Jenderal Ahmad Yani, Bandung.

[5] Dedi Kardiaman, 2011. "Panduan Modul Sistem Pneumatik Menggunakan Zeliosoft", Universitas Langlangbua 